\title{
A FUNÇÃO DO PERITO CONTÁBIL JUDICIAL E SUA INFLUÊNCIA NA SOLUÇÃO DE LITÍGIOS NA PERCEPÇÃO DOS MAGISTRADOS DO MUNICÍPIO DE CÁCERES-MT
}

\author{
José Ricarte de Lima ${ }^{1}$ \\ Elias Bortoli ${ }^{2}$ \\ Nelson Ortega da Silva ${ }^{3}$
}

\section{RESUMO}

Após análise do atual momento da situação da profissão contábil, percebe-se uma deficiência de profissionais na área de perícia contábil seja por falta de capacitação, ou ainda, por este mercado de trabalho, não estar atraindo o interesse dos profissionais da área. Desta forma, a pesquisa procurou demonstrar através de fundamentação teórica, elaborada a partir de estudo bibliográfico e descritivo, a importância, os objetivos e as necessidades que envolvem a perícia dentro do campo contábil. Para tanto, aplicou-se um questionário com perguntas abertas, aos juízes das varas cíveis do fórum da comarca do município de Cáceres, MT, com intuito de verificar na percepção dos magistrados qual a relevância do perito contador na solução de litígios, e também, se o número de profissionais nesta área é suficiente para atender a demanda do município. Os resultados da pesquisa confirmam a importância do perito contador na elucidação de processos que necessitam de seus serviços, e também expõem o tipo de litígio onde o perito contador é mais exigido, e a satisfação da maior parte dos juízes com a quantidade de peritos no município.

Palavra chave: Perícia. Judicial. Perito Contador.

\section{INTRODUÇÃO}

O poder judiciário, em algumas situações se vê obrigado a recorrer à especialista para que se esclareçam certos assuntos de outras áreas que não a de Ciências Jurídicas. Assim, verifica-se a existência de diversos especialistas denominados de Peritos do Juízo, que atuam nas mais diferentes áreas, a saber: Contábeis, Administração, Economia, Medicina, Engenharia, Agronomia e outros. O termo "perito" é previsto no Código de Processo Civil (CPC), em seus artigos 145 e 421. Nos referidos artigos a legislação determina que quando a prova do fato depender de conhecimento técnico ou científico, o juiz será assistido por perito, segundo o disposto no artigo 145. No artigo 421 o CPC diz: “O juiz nomeará o perito, fixando de imediato o prazo para entrega do laudo".

\footnotetext{
${ }^{1}$ Professor Graduado em Ciências Contábeis e mestre em Ciências Sociais. Professor Assistente no Curso de Graduação em Ciências Contábeis da Universidade do Estado de Mato Grosso - UNEMAT campus de Cáceres. E-mail: ri.carte007@ hotmail.com

${ }^{2}$ Professor Graduado em Ciências Contábeis e mestre em Ciências Sociais. Professor Auxiliar no Curso de Graduação em Ciências Contábeis da Universidade do Estado de Mato Grosso - UNEMAT campus de Cáceres. E-mail: eliasbortoli@unemat.br ${ }^{3}$ Graduado em Ciências Contábeis. E-mail: ortega5contabil@gmail.com 
A função do perito contábil judicial e sua influência na solução de litígios na percepção dos magistrados do município de Cáceres-MT

José Ricarte de Lima

Elias Bortoli

Nelson Ortega da Silva

No Brasil a modalidade em perícia passou a ser desenvolvida como uma especialidade a partir da promulgação do CPC de 1939, oferecendo aos profissionais da área oportunidade de participar das decisões judiciais. Novas e consideradas melhores regras foram estabelecidas com o Decreto Lei 9.295 de 27 de maio de 1946, onde estabelecia a criação do Conselho Federal de Contabilidade (CFC) definido às atribuições do contador e institucionalizando a Perícia Contábil no Brasil.

Assim, perícia contábil passa a ser vista como uma das áreas de atuação mais importantes da contabilidade. Função específica ao contador que deve possuir, além da condição legal, capacidade técnica, idoneidade moral e responsabilidade para exercer tal responsabilidade. Nos dias atuais a atividade de perito contador está sendo cada vez mais solicitada, mas, em decorrência dessa demanda a disponibilidade desses profissionais tem si apresentado dificultosa. Para tanto, exige-se do profissional uma educação continuada e sistemática dedicação aos princípios legais e éticos. O trabalho do perito contador exige uma rigorosa análise e certificação de documentos para a apreciação dos fatos da lide, mas seu trabalho deverá ficar restrito às informações contidas a matéria objeto do processo. As provas levantadas pelo perito deverão expressar a realidade dos fatos, fundamentados em documentos certificados. O objeto de estudo da perícia contábil é apresentado por meio de laudo pericial, utilizado pelos magistrados na solução de determinados litígios.

Considerando que os magistrados não são técnicos em todos os assuntos demandados, existem casos em que a matéria a ser julgada precisa ser esclarecida e certificada por outros profissionais, nesse sentido, em algumas situações faz-se necessário recorrer ao auxílio do profissional contador para que se esclareçam determinados assuntos contábeis inseridos nos processos instaurados nas diversas comarcas do país. Portanto, o objetivo desta pesquisa foi de um estudo para averiguar como os magistrados do município de Cáceres-MT avaliam o trabalho dos peritos contadores, e se a quantidade de peritos contábil judicial é suficiente para suprir a demanda na comarca de Cáceres-MT e região. A importância desse profissional na resolução dos litígios foi tema abordado bem como, identificar em quais litígios os peritos contadores são mais requisitado nessa comarca.

O Perito Contábil, na esfera judicial, assume a função importante de auxiliar o juiz na solução de litígios, não somente através da alegação dos fatos, mas sim na produção de provas através de documentos e demonstrações, expostos em laudo pericial contábil. O perito sendo o responsável pela execução do laudo, esse passa a ser peça fundamental em todo o processo 
A função do perito contábil judicial e sua influência na solução de litígios na percepção dos magistrados do município de Cáceres-MT

José Ricarte de Lima

Elias Bortoli

Nelson Ortega da Silva

embora não faça parte do processo. Assim sendo, estudar sua inserção nas ações judiciária perfaz caminho necessário para melhor compreender mais um campo de atuação do profissional contador.

Para que se atingissem os objetivos propostos da pesquisa foi desenvolvido um estudo bibliográfico e de campo. Na primeira parte para a realização da pesquisa bibliográfica foram utilizadas literaturas das áreas das ciências contábeis e jurídicas. De acordo com Gil (2010, p.29) a pesquisa bibliográfica é elaborada com base em material já publicado. No segundo momento o método utilizado foi o questionário com perguntas abertas. Ressalta-se que para Bervian (2003, p.48), "perguntas abertas são destinadas â obtenção de respostas livres, que possibilitem recolher dados ou informações mais ricas e variadas". $\mathrm{Na}$ amostra pesquisada as respostas foram subjetivas, sendo assim, está pesquisa tem caráter descritivo com enfoque qualitativo, com o objetivo central da investigação que é de identificar de qual forma está sendo avaliado o trabalho do perito contador pelos magistrados, e sua influência na solução dos processos no judiciário no âmbito da comarca do município de Cáceres-MT. Os participantes desta pesquisa foram os juízes que atuam nas varas cíveis do fórum do Município de Cáceres. O exame foi composto por 04 (quatro) magistrados, sendo que desse número apenas um não respondeu ao questionário enviado, e não justificou o motivo. A análise dos dados deu-se a partir da construção cuidadosa do corpus, organizado durante os trabalhos e, utilizando-se da técnica da análise de conteúdo, ou seja, do material coletado durante a pesquisa de campo (BARDIN, 2009) foram formadas as opiniões e respostas aos objetivos propostos. Cabe ressaltar, que para a análise dos dados os participantes serão tratados por letras do alfabeto no intuito de preservar suas imagens.

\section{REFERENCIAL TEÓRICO}

\subsection{Aspectos Históricos, legais e conceituação da perícia Contábil}

O vocábulo perícia surgiu do latim: peritia, que em seu sentido essencial quer dizer: "Conhecimento (adquirido pela experiência), bem como Experiência".

No começo da civilização, as pessoas consideradas experientes ou com um grande poderio físico, eram respeitadas e tidas como líderes dos grupos, elas desempenhavam o papel 
A função do perito contábil judicial e sua influência na solução de litígios na percepção dos magistrados do município de Cáceres-MT

José Ricarte de Lima

Elias Bortoli

Nelson Ortega da Silva

de perito, legislador e executor dos assuntos que precisavam de seu auxílio ou aprovação, cabendo a eles o dever de julgar e executar as leis, tudo isso pelo seu próprio ponto de vista. Há registros, na Índia, do surgimento do árbitro eleito pelas partes que desempenhava o papel de perito e juiz ao mesmo tempo. Também há vestígios de perícia nos antigos registros da Grécia e do Egito, com o surgimento das instituições jurídicas. Porém, a figura do perito, ainda fica associada ao do árbitro, definida no direito romano primitivo, no qual o laudo do perito constituía a própria sentença. Depois da Idade Média, com o desenvolvimento jurídico ocidental, a figura do perito desvinculou-se da do árbitro, (ALBERTO, 2002).

Alberto (2002) diz que a partir do século XVII, criou-se definitivamente a figura do perito como auxiliar da justiça, e ao perito extrajudicial, permitindo assim a especialidade do trabalho judicial.

No Brasil, no ano de 1939, foram estabelecidas, no Código de Processo Civil (CPC) as primeiras regras sobre perícia. Com o decreto-lei 9.245 de 1946, foram criados o Conselho Federal de Contabilidade (CFC) e os Conselhos Regionais Contabilidade (CRC), somente aí é que foram definidas as atribuições dos profissionais da contabilidade e a competência para a realização de perícias. As regras sobre perícia ainda continuaram vagas até a promulgação do Código de Processo Civil de 1973, quando a legislação tornou-se mais clara, ampla e aplicável (MAGALHÃES, 2004).

O Conselho Federal de Contabilidade em 1992 definiu as atribuições do contador nas resoluções 731 e 733, criando as Normas Técnicas de Perícia Contábil (NBC-T-13) e as Normas Profissionais do Perito Contábil (NBC-P-2), definindo com essas normas padrões comportamentais para a perícia e também ao perito.

A Perícia Contábil, portanto, é uma especialidade da contabilidade, que funciona com o objetivo específico de resolver questões contábeis, ordinariamente originárias de controvérsias, dúvidas e de casos específicos determinados ou previstos em lei. Ela enquadrasse na categoria de Prova Pericial como um instrumento de constatação, prova ou demonstração, dos fatos objeto da lide. Segundo Ornelas (2011, p. 15)

A Perícia Contábil inscreve-se num dos gêneros de prova pericial, ou seja, é uma das provas técnicas à disposição das pessoas naturais ou jurídicas, e serve como meio de prova de determinados fatos contábeis ou de questões contábeis controvertidas.

A Perícia Contábil é um exame profundo realizado por profissionais de extrema capacidade técnica - cientifica para resolver questões duvidosas relacionadas à contabilidade, 


\title{
A função do perito contábil judicial e sua influência na solução de litígios na percepção dos magistrados do município de Cáceres-MT \\ José Ricarte de Lima \\ Elias Bortoli \\ Nelson Ortega da Silva
}

servindo assim, como prova de esclarecimento ou confirmação de determinada afirmação.

Esta definição se fundamenta nos conceitos a serem abordados.

Para as Normas Brasileiras de Contabilidade perícia contábeis constitui:

\begin{abstract}
Conjunto de procedimentos técnicos e científicos destinados a levar à instância decisória elementos de prova necessários a subsidiar à justa solução do litígio, mediante laudo pericial contábil, e ou parecer pericial contábil, em conformidade com as normas jurídicas e profissionais, e a legislação específica no que for pertinente (NBCT 13 CFC, 1999, p. 01).
\end{abstract}

Para Sá, perícia contábil é a verificação de fatos ligados ao patrimônio individualizado visando oferecer opinião, mediante questão proposta. Nesse sentido, para tal opinião faz-se necessária a realização de procedimentos como: exames, vistorias, indagações, investigações, avaliações, arbitramentos, em suma todo e qualquer procedimento necessário à opinião. (2002, p. 14).

A Perícia, pode ser entendida como um trabalho de natureza especifica, significa que trata de trabalho especializado, feito com objetivo de obter prova ou opinião sobre determinado objeto. Sendo assim, a perícia pode ser realizada em todas as áreas do conhecimento, cientifica ou não. Para se fazer perícia é necessário que o profissional seja profundo conhecedor na matéria em questão e também das legislações pertinentes, e entenda a sua importância na elucidação de litígios. Para Alberto (2002, p.48), "Perícia Contábil é um instrumento técnico-científico de constatação, prova ou demonstração, quanto à veracidade de situações, coisas ou fatos oriundos das relações efeitos e haveres que fluem do patrimônio de quaisquer entidades".

Portanto, entende-se que o primeiro objetivo da perícia é a constatação, prova, ou demonstração contábil da verdade real da matéria em discussão no processo esclarecendo e oferecendo informações concretas ao juízo.

A perícia contábil tem seu foco nos fatos ou questões contábeis relacionados com a lide, dos quais deveram ser investigadas pelo perito, obedecendo a certos limites, ou seja, um conjunto de procedimentos que deve ser levados em consideração no momento da elaboração do plano de trabalho a ser executado.

Segundo Ornelas (2011), há procedimentos a serem seguidos na perícia contábil, entre eles: a limitação da matéria; pronunciamento adstrito à questão ou questões propostas; meticuloso e eficiente exame do campo prefixado; escrupulosa referência à matéria periciada; imparcialidade absoluta de pronunciamento. 
A função do perito contábil judicial e sua influência na solução de litígios na percepção dos magistrados do município de Cáceres-MT

José Ricarte de Lima

Elias Bortoli

Nelson Ortega da Silva

As questões contábeis que surgem nos processos judiciais podem ser expostas pelo magistrado, dando ao profissional contador a possibilidade de participar das decisões judiciais. Porém, o perito deve concentrar todos seus esforços tão somente nos elementos objetos da contabilidade verificados nos autos do processo em questão. A clareza e objetividade devem ser parte na elaboração da perícia, procurando sempre técnicas propicias para cada caso, seguindo o que foi solicitado, devendo também refletir sua posição de imparcialidade absoluta.

Dessa forma Alberto (2002, p.46), define o objeto da perícia contábil assim: “a perícia será de natureza contábil sempre que recair sobre elementos objetivos, constitutivos, prospectivos ou externos, do patrimônio de quaisquer entidades". Logo, o objeto da perícia contábil vai ser sempre um conjunto de situações, coisas ou fatos referentes ao patrimônio total ou parcial de quaisquer entidades.

\subsection{Prova pericial e suas modalidades}

Considerando que o trabalho pericial busca a verdade dos fatos existentes dentro do processo, cabe-nos falar o que seja prova pericial. Existem vários tipos de prova admitida pela legislação no âmbito judiciário, a saber, depoimento pessoal, confissão, exibição de documento ou coisa, testemunho, perícia e inspeção judicial.

A Prova Pericial Contábil ou simplesmente Perícia Contábil, é um instrumento utilizado para auxiliar os magistrados na solução de litígios em processos judiciais. É uma ferramenta de uso cientifico ou técnico que o perito contador pode utilizar, dessa forma, gerando a responsabilidade por fazer a demonstração de provas através de laudos.

Como descreve Ornelas (2011) a prova pericial possui função de transformar os fatos relativos à lide, sendo de natureza técnica ou cientifica, em verdade formal, em certeza jurídica. O estudo da prova pericial contábil envolve o conhecimento e o domínio de noções fundamentais quanto ao instituto da prova, qual a função da prova, a quem compete o ônus da prova, os meios de provas contábeis disponíveis e também, sobre os tipos de provas a respeito dos quais o perito estará desenvolvendo seu trabalho. Vários são os fins para os quais se podem requerer uma perícia, mas, como prova que ela se constitui, é preciso que se baseie em elementos verdadeiros e competentes. 
A função do perito contábil judicial e sua influência na solução de litígios na percepção dos magistrados do município de Cáceres-MT

José Ricarte de Lima

Elias Bortoli

Nelson Ortega da Silva

O ônus da prova é um instrumento usado para definir o responsável por dar suporte a certa afirmação. Especifica que a pessoa responsável por uma determinada afirmação deve oferecer as provas necessárias para certificar e/ou comprovar sua acusação. Ainda destaca Ornelas (2011, p.09), "que ninguém é obrigado a produzir provas, porém arcará com as conseqüências se não fizer". De acordo com Ornelas (2011) o dever de provar compete a quem alega a quem afirma ou nega determinados fatos da causa. O artigo 333 do Código de Processo Civil (2009) relata que Ônus da prova incumbe - ao autor, quanto fato constitutivo do seu direito; ao réu, quanto à existência de fato impeditiva, modificativa ou extintiva do direito do autor.

De acordo com a NBC $\mathrm{T} 13$, em seu item 13.4.1 os procedimentos periciais visam fundamentar as conclusões que serão levadas ao laudo pericial contábil e esses procedimentos são divididos em: exame, vistoria, investigação, arbitramento, mensuração, avaliação e certificação.

Ainda segundo NBC T 13 item 13.4 e itens subseqüentes às modalidades se distinguem em exame que pode ser entendido como a análise de livros, registro das transações e documentos; vistoria é a diligência que objetiva a verificação e a constatação de situação, coisa ou fato, de forma circunstancial; indagação entende-se pela busca de informações mediante entrevista com conhecedores do objeto da perícia; a investigação é pesquisa que busca trazer ao laudo pericial contábil ou parecer pericial contábil o que está oculto por quaisquer circunstâncias; arbitramento traduz-se na determinação de valores ou a solução de controvérsia por critério técnico; a mensuração é ato de quantificação física de coisas, bens, direitos e obrigações; avaliação é o ato de estabelecer o valor de coisas, bens, direitos, obrigações, despesas e receitas e, a certificação é ato de atestar a informação trazida ao laudo pericial contábil pelo perito-contador, conferindo-lhe caráter de autenticidade pela fé pública atribuída a este profissional.

Essas modalidades são desenvolvidas na etapa de investigação do processo, tendo por fim, transmitir aos autos a prova técnica que comprove as afirmações oferecidas na lide, na busca da verdade jurídica. Todos os meios são validos para que o perito forme sua opinião, evidenciando sempre a verdade dos fatos.

Em relação às espécies de perícia muitos são os casos para os quais se requer a perícia contábil, onde se envolvem fatos patrimoniais de pessoas físicas ou jurídicas, consequentemente, onde há dúvidas, a perícia contábil poderá auxiliar. Sendo assim, "este 
A função do perito contábil judicial e sua influência na solução de litígios na percepção dos magistrados do município de Cáceres-MT

José Ricarte de Lima

Elias Bortoli

Nelson Ortega da Silva

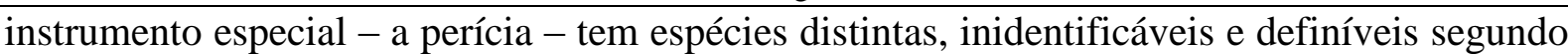
os ambientes em que é instada a atuar" (ALBERTO, 2002, p.53). Assim sendo, as espécies periciais podem ser identificada entre outras em: perícia judicial, perícia semijudicial, perícia extrajudicial e a perícia arbitral. Logo, grande é o campo de atuação do Perito contábil.

Portanto, por Perícia Judicial entende aquela realizada dentro dos procedimentos processuais do Poder Judiciário. Semijudicial realizada dentro do aparato institucional do Estado, mas fora do Poder Judiciário. Essa se enquadra no âmbito dos inquéritos policiais, comissões parlamentares, inquéritos na Administração Pública, tributária e conselhos de contribuintes. Atuante em âmbito policial e na área administrativa tributária - Tribunal de Contas. Perícia Extrajudicial é a perícia levada a efeito fora do processo judicial. Podemos dizer que a perícia extrajudicial é a perícia amistosa consentida pelas partes. Realizada fora do Estado, pela escolha de entes físicos ou jurídicos particulares, para testar a matérias e assuntos duvidosos e conflitantes, visando comprovações de fraudes, desvios e simulações. Arbitral quando a instância decisória é criada pelas partes, tem as características da judicial e extrajudicial, dividindo em decisória e probante. É aquela realizada no Juízo arbitral, instância decisória criada pela vontade das partes. As decisões servem para dirimir futuras controvérsias ou antecipar a justiça, diminuindo ou evitando a instauração de litígios judiciais. É executada por um perito, tendo valor igual à judicial, mas suas regras são escolhidas pelos litigantes, sendo assim de natureza extrajudicial.

Cabe-nos ressaltar que a perícia contábil judicial objetiva a busca de informações dentro do poder judiciário. Assim sendo, perícia contábil judicial é um dos instrumentos de prova que os juízes e advogados utilizam para identificação da verdade formal, dentro dos fatos acontecidos, objeto da lide. É realizada dentro dos procedimentos processuais do Poder Judiciário, seja por determinação, requerimento ou até pela necessidade de seus agentes ativos, e se processa segundo regras legais específicas.

A instalação de uma Perícia Judicial poderá ser provocada por uma das partes interessadas ou no entendimento do Juiz, em caso de o processo não apresentar elementos suficientes de convencimento que a um julgamento justo. A perícia judicial surgirá sempre que o magistrado não for suficiente apto para realizar a verificação dos fatos que desencadearam o litígio, seja pela ausência de conhecimentos técnicos ou científicos, sejam pela impossibilidade de colher os dados necessários para o deslinde da questão. É o que dispõe o artigo 145, concomitante com o artigo 421, do CPC. 
A função do perito contábil judicial e sua influência na solução de litígios na percepção dos magistrados do município de Cáceres-MT

José Ricarte de Lima

Elias Bortoli

Nelson Ortega da Silva

A partir deste momento, surge a figura do perito como auxiliar da justiça, que assessora o juiz na formação de seu convencimento. A função deste profissional reside, portanto, no processo investigativo dos fatos apontados na lide. Segundo Sá (2004, p.63), "Perícia Contábil Judicial é a que visa servir de prova, esclarecendo o juiz sobre assuntos em litígio que merecem seu julgamento, objetivando fatos relativos ao patrimônio aziendas das pessoas".

\subsection{Nomeação do perito e seus honorários}

A decisão do juiz em instalar uma perícia é tomada no momento do despacho saneador, exarado nos autos do processo, motivado pelo fato do magistrado depender do conhecimento especializado de um profissional para trazer aos autos provas que esclareçam os pontos controvertidos existentes no processo. Nele, além da nomeação do perito contábil, outras decisões são tomadas pelo magistrado, como o prazo para as partes oferecerem quesitos e indicar, caso queiram, seus assistentes técnicos, além do que poderá ele próprio, formular seus quesitos. A nomeação será pelo juiz, de acordo com as necessidades do litígio, os juízes é quem determinam as perícias, e na escolha do perito. A escolha do perito contador é realizada pelo magistrado, através da nomeação, sendo este citado por meio de intimação via cartório. A intimação é a ação de dar conhecimento ao perito de sua nomeação feita pelo juiz. Cabe ao perito dizer se é capacitado ou se está impedido para exercer tal função pelos motivos estabelecidos na lei vigente, está atitude se caracteriza como escusa do perito. Sendo assim o perito tem o dever de cumprir o ofício ao qual foi nomeado, mas a lei garante o direito de escusar-se do encargo, conforme o que diz o art. 146 do CPC.

A NBC P 2 item 2.3.4, diz:

A indicação ou a contratação para o exercício da atribuição de perito-contador assistente deve ser considerada como distinção e reconhecimento da capacidade e honorabilidade do Contador, devendo este recusar os serviços sempre que reconhecer não estar capacitado a desenvolvê-los, contemplada a utilização de serviços de especialistas de outras áreas, quando parte do objeto do seu trabalho assim o requerer. 
A função do perito contábil judicial e sua influência na solução de litígios na percepção dos magistrados do município de Cáceres-MT

José Ricarte de Lima

Elias Bortoli

Nelson Ortega da Silva

Cabe dizer que a legislação faculta o profissional a recusar caso assim decida. Desta forma, no artigo 146 parágrafo único do $\mathrm{CPC}$, diz que o perito pode escusar-se do encargo alegando motivo legitimo, dentro de cincos dias de sua intimação ou do impedimento superveniente, sob pena de se reputar renunciando o direito de alegá-lo.

Em relação aos honorários periciais Ornelas (2011) comenta que ao aceitar o encargo confiado, o perito deverá apresentar, por meio de petição, a sua proposta de honorários dentro do prazo estabelecido, geralmente de cinco dias, recomendando-se a apresentação de um plano de trabalho detalhado, estimando o número de horas previstas para a execução do trabalho, mediante avaliação dos serviços, considerando, entre outros, aos fatores da relevância, do vulto, do risco, da complexidade e outros fatores, mas quem fixará o valor a ser pago ao perito é o juiz, esse ato processual é conhecido como arbitramento. É de lembrar que neste caso o responsável pelos honorários periciais é a parte que requereu o exame, é o que $\operatorname{diz}$ CPC:

Art. 19 - Salvo as disposições concernentes á justiça gratuita, cabe as partes prover as despesas dos atos que realizam ou requerem no processo, antecipando-lhes o pagamento desde o inicio até sentença final [...].

Art. 20 - A sentença condenara o vencido a pagar o vencedor as despesas que antecipou e os honorários advocatícios. [...].

Os valores a serem fixados como honorários também devem levar em conta o números de horas trabalhadas.

Alberto (2002, p.155), ensina que o magistrado habitualmente considera para a fixação dos honorários a importância, complexidade e qualidade do trabalho apresentado, dado que este é de grande valia ao juiz; a perfeição técnica; os fundamentos e custos demonstrados pelo perito; a capacidade econômica-financeira das partes, e ainda a importância econômica da ação para as partes.

Estabelece o artigo 421 do CPC, que o juiz ao nomear o perito, desde já fixará o prazo pra entrega do laudo e, no artigo 433 diz que - o perito apresentará o laudo em cartório, no prazo fixado pelo juiz, pelo menos 20 (vinte) dias antes da audiência de instrução e julgamento. No seu parágrafo único, ressalta que os assistentes técnicos oferecerão seus pareceres no prazo comum de 10 (dez) dias, depois de intimadas as partes da apresentação do laudo. 
A função do perito contábil judicial e sua influência na solução de litígios na percepção dos magistrados do município de Cáceres-MT

José Ricarte de Lima

Elias Bortoli

Nelson Ortega da Silva

$\mathrm{Na}$ impossibilidade de cumprimento do prazo, deve o perito contador requerer prazo suplementar, sempre por escrito é o que determina a NBC T 13, em seu item 13.2.1.2.1.

Assim, é de fundamental importância que o perito tenha pleno conhecimento da questão, dos fatos envolvidos, bem como dos recursos disponíveis para o seu exame, para que possa planejar adequadamente o seu trabalho, a fim de cumprir o prazo estipulado, ganhando com isso reconhecimento do juiz pela sua competência e responsabilidade na execução de seus trabalhos.

\section{Análise e Interpretação dos Dados}

Diante das informações coletadas, nota-se o reconhecimento dos magistrados para com a importância dos peritos contadores como auxiliares da justiça, pois é através do laudo confeccionado pelo profissional perito que os juízes podem sanar suas dúvidas em relação aos assuntos que fogem de seus conhecimentos, nesse caso, a própria contabilidade. Também foi detectada que o serviço para o qual o perito é mais exigido é a revisão contratual, principalmente por si tratar de cálculos técnico-contábeis. Existe a necessidade de os peritos em seus laudos serem mais explícitos, expondo com clareza suas opiniões para facilitar a decisão dos juízes, e para que isso ocorra o contador deve procurar compreender as controvérsias dos processos. Em relação a falta de profissionais para atender a demanda constatou-se que na região há grande número de escritórios contábeis e, partindo da ideia de que a Universidade do Estado de Mato Grosso por estar nessa região e, oferecer o curso de Ciências Contábeis, é difícil concluir que exista falta de profissionais para aturem nessa área. Porém, percebe-se que os profissionais contadores não são atraídos por esse mercado de trabalho, ou não se sentem preparados para assumir tal responsabilidade. Cabe ressaltar que dois dos três magistrados participantes da pesquisa responderam que estão satisfeitos com o número de peritos contadores inscritos para trabalharem nessa área, caso haja necessidade.

\subsection{A Atuação do Perito Contador na visão dos Magistrados}

A Análise do entendimento da atuação do perito contador na perspectiva dos magistrados que participaram da amostra foi realizada a partir das questões propostas para os Volume 3, Número 5 Revista UNEMAT de Contabilidade 
A função do perito contábil judicial e sua influência na solução de litígios na percepção dos magistrados do município de Cáceres-MT

José Ricarte de Lima

Elias Bortoli

Nelson Ortega da Silva

mesmos. Portanto, a seguir serão expostos os questionamentos e suas respectivas respostas.

Salienta-se que os participantes da pesquisa, ou seja, os magistrados serão identificados por letras do alfabeto no intuito de preservar suas identidades.

Procurou-se saber dos magistrados se na realização da sentença é utilizado o laudo pericial e, se caso isso aconteça, o conteúdo constante é relevante no momento da decisão ou apenas contribui?

Resposta do participante A: Em muitas sentenças há a necessidade do laudo pericial, e dependendo da perícia principalmente se for altamente técnica o conteúdo é relevante para a sentença.

Resposta do participante B: Sim, é utilizado e é relevante ao passo que contribui para formar a convicção dos julgados no momento de decidir.

Resposta do participante C: Sim. O conteúdo costuma ser relevante principalmente se o perito demonstra sólida fundamentação em suas conclusões.

Portanto, percebe-se que todos são unânimes em considerar que o conteúdo do laudo é importante no ato decisório e este na maioria das vezes é relevante e levado em consideração. Deste modo, nota-se que o trabalho pericial tem considerável influencia na decisão sentencial.

Quando o questionamento é: Que tipo de litígio V.Exa. requisita o auxílio de um perito contábil? As respostas são as seguintes:

Participante A: Revisão de contratas, principalmente contratos bancários.

Participante B: Ações de Revisão contratual e cobrança.

Participante C: Normalmente quando não há possibilidade de mera interpretação literal das cláusulas e os cálculos são questionados de modo técnico contábil. Ex.: Revisão contratual de controladas.

Dessa forma, é possível notar que os juízes mais requerem o auxilio do perito nos casos de revisão contratual, sendo que apenas um acrescentou cobrança.

Percebe-se primeiro que a revisão contratual é o tipo de processo onde o perito contador do nosso município Cáceres-MT é mais requisitado e, segundo a dificuldade dos magistrados em solucionar questões que envolvam cálculos de modo técnico-contábil.

No laudo, os peritos destacam os fatos processuais relevantes para o bom desenvolvimento do trabalho? Em relação a esse questionamento dois magistrados responderam que nem todos os peritos ressaltam as peças relevantes para o bom desenvolvimento do trabalho, e apenas um concordou que os peritos realizam tal 
A função do perito contábil judicial e sua influência na solução de litígios na percepção dos magistrados do município de Cáceres-MT

José Ricarte de Lima

Elias Bortoli

Nelson Ortega da Silva

procedimento. Daí concluir, que nem todos os peritos destacam os fatos importantes que fundamentam a lide, e isso de fato é o que traria maior transparência e segurança nas informações apresentadas. Veja a seguir as respostas dos magistrados para esse questionamento:

Participante A: Sim, os peritos têm acesso aos autos e realizam o trabalho com minúcia.

Participante B: Geralmente sim.

Participante $\mathbf{C}$ : Alguns peritos realizam tal conduta.

Em sua opinião existem peritos suficientes para atender a demanda dos processos no município de Cáceres? Dois dos pesquisados responderam positivamente e apenas um respondeu negativamente, e acrescentou "muitas vezes nomeiam-se peritos de fora".

Resposta do participante A: Não, muitas vezes nomeiam-se peritos de fora.

Resposta do participante B: Sim.

Resposta do participante C: Creio que sim.

Ressalva-se que, em primeiro lugar não foi investigado profundamente a forma como os peritos são nomeados, em segundo foi constatado que não há na comarca um quadro de peritos, ou seja, não existem peritos inscritos no fórum, as nomeações se dão por indicações. O magistrado que respondeu negativamente pode ter várias razões, ele pode não estar satisfeito realmente com o número de profissionais, por não atenderem do seu ponto de vista a sua demanda, ou não estar satisfeito com forma como esses peritos desenvolvem seus trabalhos.

A pesquisa buscou saber entre outras informações, de que forma o magistrado avalia a importância do perito contador, no auxilio a solução de litígios. Nesse sentido, os magistrados ressaltaram a importância do perito como assessor do juiz na solução de litígios, pois, o perito atua na área onde os magistrados não possuem domínio técnico.

\section{CONSIDERAÇÕES FINAIS}

Assim, com base nas fundamentações expostas e os resultados obtidos na pesquisa, é possível compreender que o Perito Contábil Judicial é um especialista da Contabilidade que trabalha os aspectos duvidosos em processos judiciais, desempenhando um papel importante 
A função do perito contábil judicial e sua influência na solução de litígios na percepção dos magistrados do município de Cáceres-MT

José Ricarte de Lima

Elias Bortoli

Nelson Ortega da Silva

para a sociedade, uma vez que o laudo constitui um instrumento capaz de fornecer informações a fim de elucidar questões litigiosas.

A Perícia Contábil é uma especialidade do Contador que não exige nenhuma pósgraduação, muito menos dedicação exclusiva, podendo o contador desenvolver outro trabalho na área contábil, onde com certeza irá contribuir com a qualidade do trabalho pericial, pois um bom perito deve ter experiência em sua área de atuação. Para consecução de qualquer perícia, o perito contador precisa ter profundos conhecimentos contábeis e entender sobre outras áreas correlacionadas com a sua, como direito, economia, administração e várias outras. O Perito necessita ter para desenvolver um bom trabalho que é a confecção do laudo pericial, alguns requisitos fundamentais como: saber técnico, vivência profissional, perspicácia e sagacidade e índole criativa e intuitiva.

O laudo pericial tem uma influência significativa na tomada de decisão pelos magistrados, constituindo um meio de prova da matéria apreciada, assegurando maior embasamento, trazendo transparência nas questões contábeis e servindo como orientador das decisões.

A pesquisa permitiu concluir, que segundo na percepção dos magistrados o papel do Perito Contador Judicial é muito importante, pois a função do perito é auxiliar em questões fora do conhecimento dos juízes, dirimindo as dúvidas que inviabilizavam o procedimento dos processos judiciais. A amostra revelou também que a maior parte dos magistrados estão sim satisfeitos com o número de perito contadores no município.

\section{REFERÊNCIAS}

ALBERTO, Valder Luiz Palombo. Perícia Contábil. $3^{\circ}$ edição. São Paulo: editora Atlas 2002.

BARDIN, Laurence. Análise de conteúdo. 4. ed. Lisboa: Geográfica, 2009.

BERVIAN, Amado L. Cervo Pedro A. Metodologia Cientifica, $5^{\circ}$ edição, São Pulo: Prentice Hall, 2003.

BRASIL. Lei $\mathrm{n}^{\mathrm{o}}$ 5.869, de 11 de janeiro de 1.973. Institui o Código de Processo Civil. Brasília, Congresso Nacional, 1973. 
A função do perito contábil judicial e sua influência na solução de litígios na percepção dos magistrados do município de Cáceres-MT

José Ricarte de Lima

Elias Bortoli

Nelson Ortega da Silva

CONSELHO FEDERAL DE CONTABILIDADE. Resolução n858, de 29 de agosto de 1.999. Institui Normas Brasileiras de Contabilidade - NBC T 13 - Da Perícia Contábil. Brasília, CFC, 1.999.

CONSELHO FEDERAL DE CONTABILIDADE. Resolução $\mathbf{n}^{\mathbf{0}} \mathbf{1 . 2 2 4 3}$, de 10 de dezembro de 2009. Institui Normas Brasileiras de Contabilidade - NBC TP 01 - Perícia Contábil. Brasília, CFC, 2009.

CONSELHO FEDERAL DE CONTABILIDADE. Resolução $\mathbf{n}^{\mathbf{0}}$ 857, de 21 de agosto de 1999. Institui Normas Brasileiras de Contabilidade - NBC P 2 - Normas Profissionais de Perito Contábil. Brasília, CFC, 1999.

GIL, Antonio Carlos. Como Elaborar Projetos de Pesquisa. $5^{\text {a }}$ ed. São Paulo: Atlas, 2010.

MAGAlHãeS, Antônio de Deus Farias et al. Perícia Contábil: uma abordagem Teórica, Ética, Legal, Processual e Operacional. $4^{\circ}$ edição. São Paulo: editora Atlas 2004.

ORNELAS, Martinho Maurício Gomes de. Perícia Contábil. 5º ed. São Paulo: Atlas, 2011.

SÁ, Antônio Lopez de. Perícia Contábil. 5º edição. São Paulo: editora Atlas 2002. Perícia Contábil. $6^{0}$ edição. São Paulo: editora Atlas 2004. 
A função do perito contábil judicial e sua influência na solução de litígios na percepção dos magistrados do município de Cáceres-MT

José Ricarte de Lima

Elias Bortoli

Nelson Ortega da Silva 